\title{
Detection of small delamination in mullite/Si/SiC model EBC system by pulse thermography
}

\author{
Yutaro $\mathrm{ARAI}^{a}$, Ryo INOUE ${ }^{b, *}$ \\ ${ }^{a}$ Department of Materials Science and Technology, Tokyo University of Science, 6-3-1, \\ Niijyuku, Katsushika-ku, Tokyo, 125-8585, Japan \\ ${ }^{b}$ Department of Mechanical Engineering, Tokyo University of Science, 6-3-1, \\ Niijyuku, Katsushika-ku, Tokyo, 125-8585, Japan
}

Received: January 20, 2019; Revised: February 28, 2019; Accepted: March 22, 2019

(c) The Author(s) 2019.

\begin{abstract}
The pulse thermography (PT) technique was applied to the detection of the delamination of a multi-layered coating system composed of mullite/Si onto a reaction-bonded $\mathrm{SiC}$ substrate. The potential evaluation was carried out in order to detect internal delamination in multi-layered material system. Moreover, the observation of the cross sections and 3D views obtained by X-ray computed tomography (CT) indicated that the delamination occurred at the interface between the top coat and the bond coat layers. The changes in the temperature distribution obtained by PT indicated the existence of a delamination area in the top coat layer of the mullite. In particular, the lower temperature region corresponded to the delamination area. The experimental results confirmed that the PT technique is effective with respect to the internal delamination of multi-layered coating system.

Keywords: environmental barrier coatings (EBCs); delamination; pulse thermography (PT); multilayer; image processing
\end{abstract}

\section{Introduction}

Environmental barrier coatings (hereafter denoted as EBCs) are key technology for surface protection of $\mathrm{SiC}$ fiber reinforced $\mathrm{SiC}$ matrix (hereafter denoted as $\mathrm{SiC} / \mathrm{SiC}$ ) composites from combustion atmosphere in an advanced aero gas turbine engine. Multi-layered EBC systems typically consist of silicate top coat layer and Si-based bond coat layer [1-8]. The coefficient of thermal expansion (hereafter denoted as CTE) of silicate top coat layer $\left((5-8) \times 10^{-6} \mathrm{~K}^{-1}[9]\right)$ is usually larger than that of $\mathrm{Si}$ bond coat layer $\left(\sim 4 \times 10^{-6} \mathrm{~K}^{-1}\right.$

*Corresponding author.

E-mail: inoue.ryo@rs.tus.ac.jp
$[10,11])$ and $\mathrm{SiC} / \mathrm{SiC}$ substrate $\left((4.5-5.5) \times 10^{-6} \mathrm{~K}^{-1}[2]\right)$. Mismatch of CTE among top coat layer, bond coat layer, and substrate generates in-plane thermal tensile stress in a silicate top coat layer and it causes mud cracks in top coat layer. In the case of air plasma sprayed coatings, shrinkage of metastable silicates during crystallization from amorphous to crystalline of silicate also leads to severe damage after heating $[12,13]$. In addition, degradations of EBC layer such as melting of $\mathrm{Si}$ and formation of cristobalite in bond coat occur [5-8,13-16] because combustion environment in aero gas turbine engine is $1300-1700{ }^{\circ} \mathrm{C}$ with $10-30$ atm and the partial pressure of $\mathrm{H}_{2} \mathrm{O}$ is 1-3 atm [17], and $\mathrm{H}_{2} \mathrm{O}$ reaches Si bond coat layer through the mud cracks in top coat layer. The formation of cristobalite causes the large tensile stress with 2-3 GPa because 
the transformation with volume shrinkage ( $4.5 \mathrm{vol} \%)$ occurs at $220{ }^{\circ} \mathrm{C}[7,14]$ and they become a driving force of delamination induced by cracks in $\mathrm{Si}$ bond coat layer and the interface between bond coat layer and top coat layer.

A simple method for detection of delamination after heat exposure as well as as-deposited coatings is required to prevent degradation taken place by excessive heating and chemical reactions. For detection of the delamination area in $\mathrm{EBC}$, determination of shape and dimensions of delamination, spectroscopic nondestructive evaluation, ultrasonic method, thermal imaging method, and X-ray computed tomography (CT) have been applied [18-20]. Spectroscopic nondestructive evaluation and X-ray CT method require complicated experimental systems. In addition, the relation between spatial resolution and inspection time of these procedures is trade-off and these procedures are not suitable for in-line inspection. Ultrasonic is used as a simple method to detect defects; however, wave decay makes the evaluation difficult. Among them, thermal imaging method seems attractive because of simple detection in ambient air condition. This method is successfully applied for delamination problem of laminated fiber reinforced ceramics [21] and impact damages of composites with $\mathrm{EBC}$ are evaluated by thermal imaging method [20]. However, direct application of thermography technique for detection of the internal damages and delamination in EBC system is not examined yet.

In the present study, major attention has been paid to evaluate potential of pulse thermography (hereafter denoted as PT) techniques for detection of $\mathrm{EBC}$ delamination from substrate with high spatial resolution condition. Thermal images and temperature profiles of EBC system measured by PT are discussed in terms of microstructures and unsteady state heat conduction.

\section{Experimental procedure}

\section{1 Specimen preparation}

This study focused on evaluating the potential application of the PT technique in the detection of delamination evolved in multi-layered ceramics with a high spatial resolution using a model $\mathrm{EBC}$ system composed of mullite/Si/reaction bonded $\mathrm{SiC}$ (RBSC), which is a typical model material. RBSC was selected as the substrate to neglect the heterogeneity of the $\mathrm{SiC} / \mathrm{SiC}$ substrate, e.g., the anisotropic thermal conductivity originating from the fiber arrangement, pore within matrix, and inter-bundles. The RBSC contained $\sim 80$ $90 \mathrm{vol} \%$ of dispersed small $\alpha$-SiC particles (diameter $100-800 \mu \mathrm{m})$ and $\sim 10-20$ vol\% of free-silicon $(\mathrm{Si})$. The RBSC block was cut into disk-shape pieces with a diameter of $\sim 12.7 \mathrm{~mm}$ and a thickness of $\sim 2 \mathrm{~mm}$. Thereafter, one side was carefully polished up to a diamond paste finish of $0.5 \mu \mathrm{m}$, and then fully cleaned with acetone under ultrasonic vibration to remove the adherent. The Si bond coat layer (purity 99\%) was deposited by using a vacuum plasma spray (VPS) process. The thickness of the Si bond coat layer was $\sim 60 \mu \mathrm{m}$. The mullite top coat layer was also deposited on the surface of the Si bond coat layer by implementing the VPS process, and the thickness was $\sim 240 \mu \mathrm{m}$. Mullite/Si/RBSC EBC system was heat-exposed in air at $1450{ }^{\circ} \mathrm{C}$ for $2 \mathrm{~h}$ by using an electric furnace. After the heat exposure, the appearance of the specimen was carefully observed. Subsequently, the specimen was embedded into an epoxy mount. Moreover, the specimens were cut and polished through a standard metallurgical process. Finally, the surface and polished sections were observed through optical and scanning electron microscopes (SEM, TM-3000, Hitachi, Tokyo, Japan).

\subsection{X-ray CT and PT}

PT was used to detect the delamination in the $\mathrm{EBC}$ system after heat exposure at $1450{ }^{\circ} \mathrm{C}$ for $2 \mathrm{~h}$. Figure 1 shows a schematic of the experimental setup.

The system was composed of two pulse light sources, high-speed infrared (IR) camera (SC7000, FLIR, France) with the flame rate of $40 \mathrm{~ms}$, and an image processing computer. The InSb IR camera had $640 \times$ 512 pixels with a special resolution of $20 \mathrm{mK}$ (at $25^{\circ} \mathrm{C}$ ). In this study, the close-up lens (observation area $5 \mathrm{~mm} \times 5 \mathrm{~mm}$ ) was applied to the detection of small delamination (typically $\sim 100-200 \mu \mathrm{m}$ ). The pulse source had a nominal output power of $500 \mathrm{~W}$ with a pulse time of $\Delta x \approx 50 \mathrm{~ms}$. The samples were heated by pulse flash, which was synchronized with the IR camera (detection wavelength range: $1.5-5.1 \mu \mathrm{m}$ ). To obtain accurate temperature profiles, the IR camera was calibrated by using a black body plastic sheet before the measurements. The observation and evaluation areas were approximately $6 \mathrm{~mm} \times 5 \mathrm{~mm}$ and $3 \mathrm{~mm} \times 3 \mathrm{~mm}$ on the surface. The experiments were conducted under ambient air and room temperature conditions. The temperature was measured for $10 \mathrm{~s}$ 


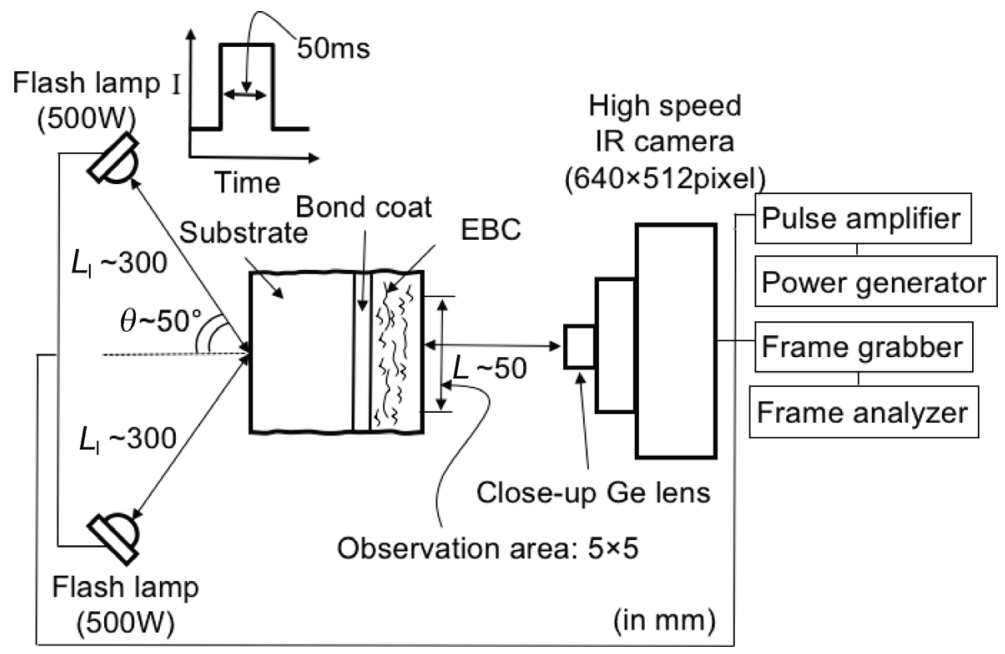

Fig. 1 Experimental setup for PT measurement.

after flash heating. In the present study, the bottom of specimen (substrate) was heated and temperature profiles for the surface were recorded to apply this method as an industrial non-destructive evaluation method.

We also obtained a 3D reconstructed image of the same EBC system used for PT by X-ray CT. In the experiments, a conventional X-ray scanner (InspecXio, SMX-225CT, Shimadzu Corp., Kyoto, Japan) was used. The voltage and tube current were set to $95 \mathrm{kV}$ and 40 $\mu \mathrm{A}$, respectively. Additionally, the field of view was set to $\sim 13 \mathrm{~mm} \times 13 \mathrm{~mm} \times 13 \mathrm{~mm}$. The number of images with a resolution of $512 \times 512$ pixels was 600 . Under these conditions, one pixel corresponded to $\sim 25 \mu \mathrm{m}$. The 2D view was reconstructed by using image processing software (myVGL, Volume Graphixs GmbH, Germany).

\section{Experimental results}

In the present study, only microstructural characterization for cracking behavior of EBC system is conducted. The detailed characterization of microstructural change of mullite/Si/RBSC EBC system used in the present study by heat exposure has already been reported elsewhere [13,14]. Figure 2 shows the specimen surface used in this study. The mud-cracking pattern was clearly observed at the top coat layer surface. Typically, one piece of the cracked top coat layer segment was in the range of $0.2-1.8 \mathrm{~mm}^{2}$. The polished cross sections are shown in Fig. 3 after heat exposure at $1450{ }^{\circ} \mathrm{C}$ for $2 \mathrm{~h}$. Two types of transverse cracks were observed in the top coat layer, namely a tunnel crack and a short

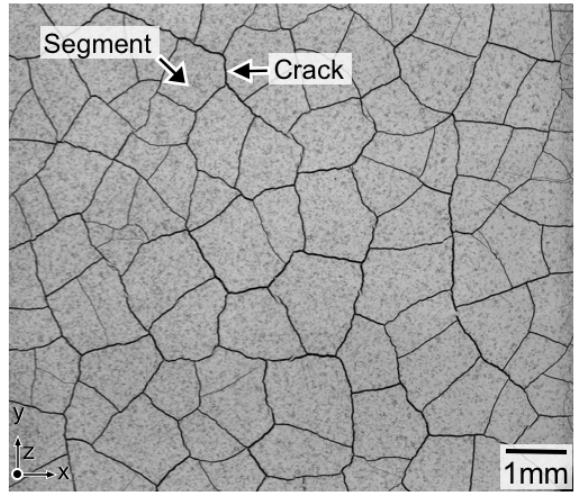

Fig. 2 Typical surface microstructure of EBC system after heat exposure at $1450{ }^{\circ} \mathrm{C}$ for $2 \mathrm{~h}$.

through-thick crack in the top coat layer. The former crack propagated along the through-the-thickness direction in the top coat layer, and deflected at the interface between the top coat and the Si bond coat layers. After deflection, the deflected crack in the Si bond coat layer propagated parallel along the interface. The propagated length was approximately $50-150 \mu \mathrm{m}$ through the cracks. The crack opening displacement (COD) and $u$ defined in Fig. 3, became smaller with the separation from the outermost surface of the top coat layer. This behavior originated from the constraint effect of the mullite top coat layer by the Si bond coat layer. During the exposure to heat, the mullite top coat layer shrank by crystallization $[15,17]$. Upon cooling down from the temperature reached during the heat exposure, the cracks tended to open because the coefficient of thermal expansion (CTE) of the top coat layer was higher than that of the RBSC substrate. The top coat layer was subjected to an in-plane tensile strain, 


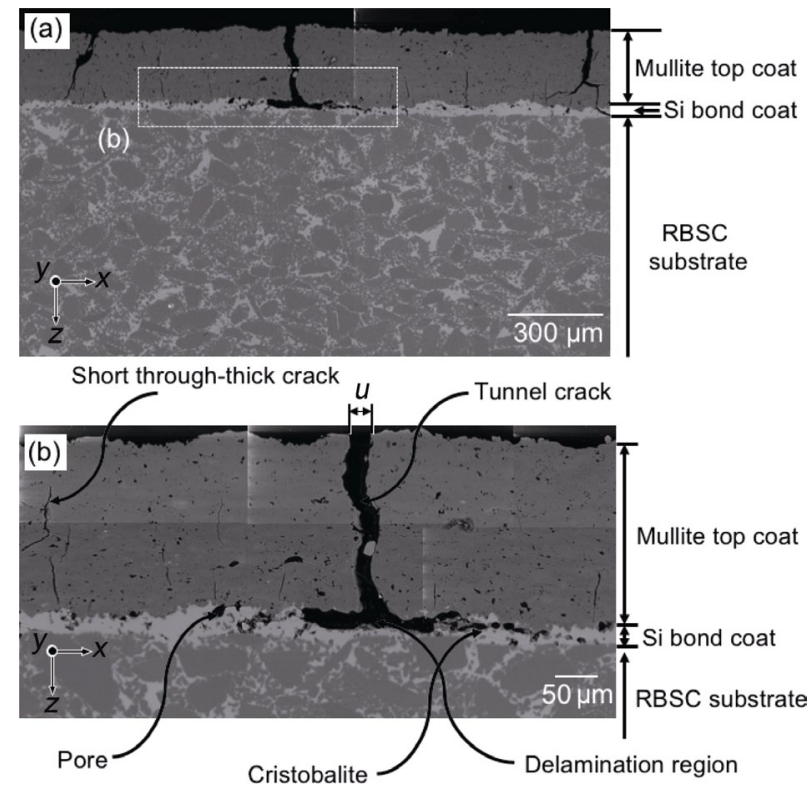

Fig. 3 (a) Transverse section of EBC system after heat exposure at $1450{ }^{\circ} \mathrm{C}$ for $2 \mathrm{~h}$, (b) an enlarged view of Fig. 3(a).

and this strain caused the shrinkage of the layer. In comparison to the outermost surface, the interface between the mullite top coat layer and the Si bond coat layer was constrained because of the smaller thermal expansion coefficient of RBSC $\left(\sim 4.5 \times 10^{-6} \mathrm{~K}^{-1}[10,11\right.$, $22])$ than that of the top coat layer $\left((5-6) \times 10^{-6} \mathrm{~K}^{-1}[9]\right)$. As a result, the shrinkage of the layer near the interface was suppressed.

Figures 4(a) and 4(b) show the $x y$-plane at the top coat/bond coat interface and $x z$-plane, which corresponded line between A and B of the model EBC system obtained by X-ray CT. Under the test conditions applied in this study, the micro-damages, such as cracks and pores at the inter-splats, were not detectable because the dimensions of these micro-damages were smaller than the spatial resolution. However, a delamination region at the interface was clearly observed. The contrast was sufficient enough to distinguish the crack and solid (mullite). The segments were not fully bonded with a $\mathrm{Si}$ bond coat layer, but rather delaminated at the interface between the mullite and $\mathrm{Si}$ bond coat layer. The penetration of the crack into the bond coat layer was not observed. These characteristics were similar to those identified by direct microstructural observation. Additionally, invisible partial delamination was detected by X-ray CT at the edges of the segment.

Figures 5(a) and 5(b) show the typical temperature distribution of the top coat layer and we defined the

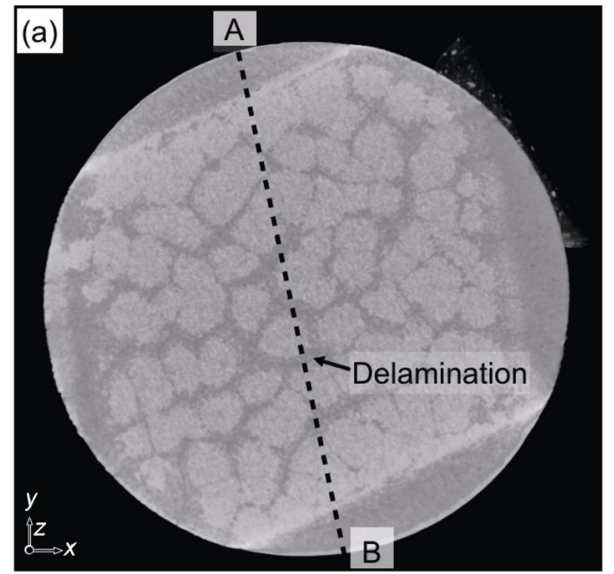

(b)

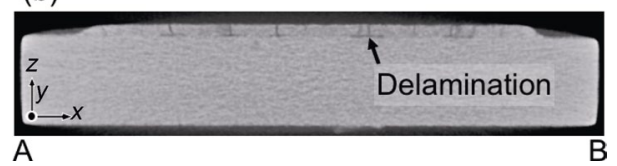

Fig. 4 Example of X-ray CT image after cracking and partial delamination: (a) $x y$-plane, (b) $x z$-plane between line $\mathrm{A}$ and $\mathrm{B}$ in (a).
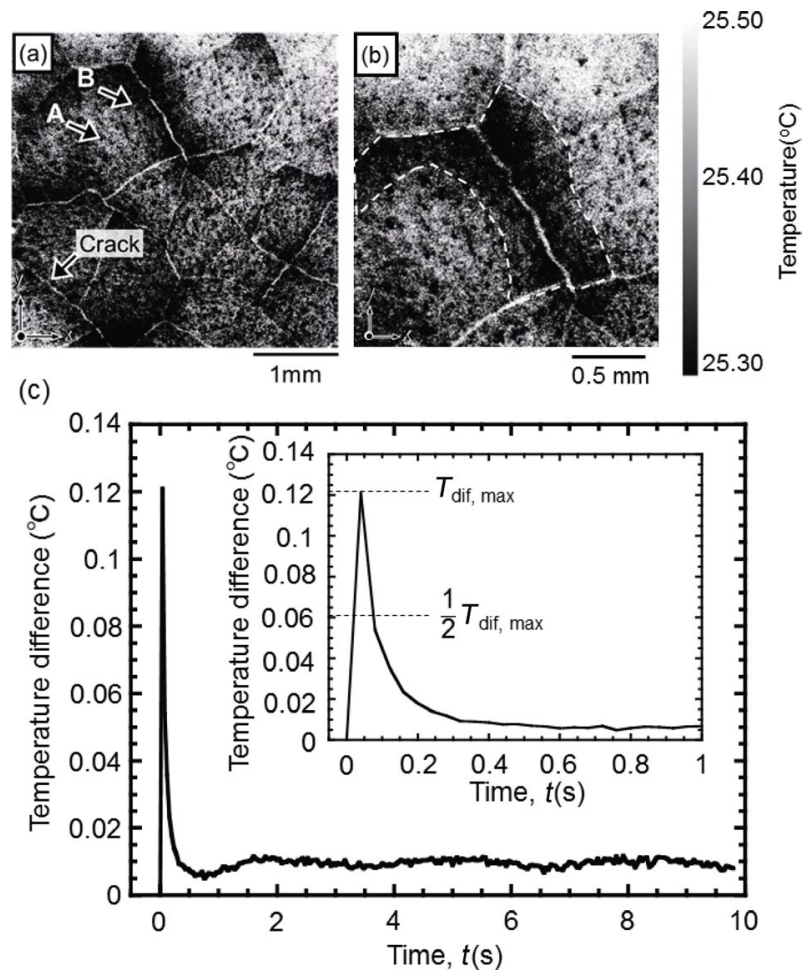

Fig. 5 (a) Typical examples of temperature distribution on surface of EBC; (b) enlarged view of (a); (c) temperature difference approximately in middle of segment and around crack.

areas with temperatures of $25.5,25.4$, and $25.3{ }^{\circ} \mathrm{C}$ as a crack, higher temperature area, and lower temperature area, respectively. Figure 5(c) shows the surface 
temperature difference between points A and B in Fig. 5(a). It is clear that the lower temperature area, surrounded by a dotted line, spreads on both sides of the transverse cracks. In comparison to these lower temperature areas, the temperature at the center of the segmented area was always higher than the temperature at the edges.

When maximum temperature difference is defined as $T_{\text {dif,max }}$, the temperature difference with $T_{\text {dif,max }} / 2$ is maintained for $\sim 100 \mathrm{~ms}$ after pulse irradiation. Thus, the temperature profile should have been collected within $\sim 100 \mathrm{~ms}$ after flush heating, since the larger temperature difference achieved a larger resolution for carrying out an evaluation by the PT method. An example of the surface temperature change within the selected area (between A and B shown in Fig. 5) on the top coat layer is shown in Fig. 6.

The result clearly shows that the lower temperature area with the length of $\sim 25$ pixels around both sides of the crack exists, and it agrees with the thermal images of PT. At the lower temperature area, the temperature was always lower than that at the higher temperature spot. In the present experiment, the pulse light illumination was carried out from the back of the RBSC surface, and this temperature difference appeared as a result of the heat transfer difference in the through-the-thick direction between points $\mathrm{A}$ and $\mathrm{B}$. Because the constituent materials were the same for

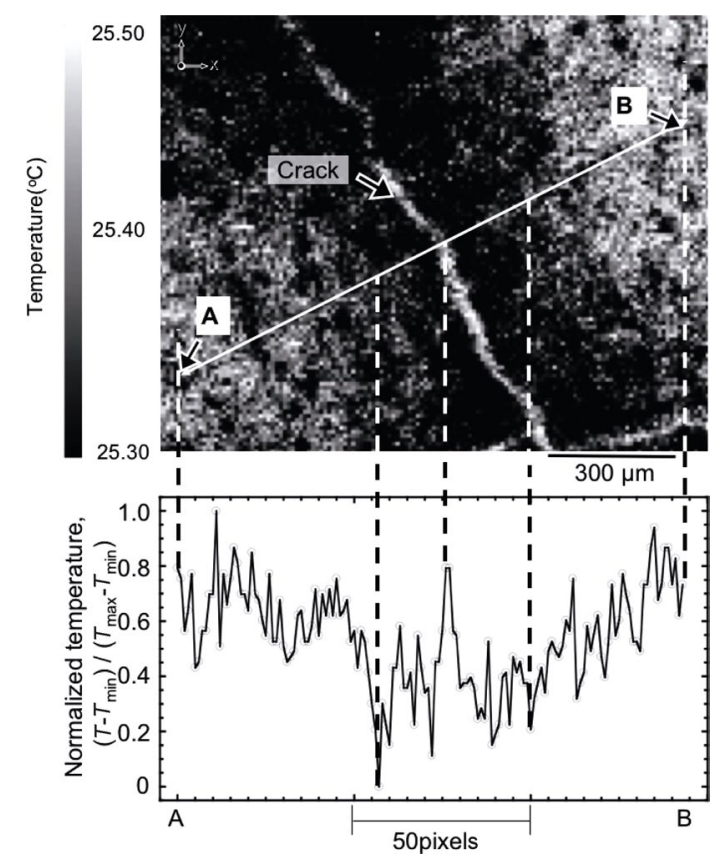

Fig. 6 Normalized temperature distribution around mud crack. both points, this temperature difference was attributed to the difference of thermal conductivity or the thermal diffusion path. Microscopically, the thermal conductivity path in the RBSC exhibited tortuosity because of the dispersed SiC particles and the connected Si phase. In comparison to the size of the lower temperature area, the size of the $\mathrm{SiC}$ particle was sufficiently small. Moreover, it is important that we were able to treat RBSC as a homogeneous material. However, when delamination occurred, thermal resistance appeared and the apparent thermal conductivity in the throughthe-thick direction became lower because delamination area is filled with air with the thermal conductivity of $0.0254 \mathrm{~W} /(\mathrm{m} \cdot \mathrm{K})[23]$. Thermal images exhibiting clear contrast could be observed in the PT study for laminates, since the temperature at the delamination region was lower than the temperature in the nondelamination area [24,25]. Consequently, it is likely that the temperature of the delaminated area became lower. However, it is difficult to determine the distribution or length of the delamination in the EBC system from the temperature profile, since it did not exist in the baseline in order to determine the high temperature and low temperature regions, i.e., the delaminated and non-delaminated areas. An example of a method of determining the baseline is discussed below.

\section{Discussion}

To quantitatively evaluate the delamination in the EBC, appropriate data processing is required for application to the detection by the PT. Moreover, because of the low $S / N$ ratio, it is impossible to select a quantitative baseline in order to divide the high temperature and low temperature regions.

The temperature profile shows the temperature of the surface, which was collected by a $1 \times 1$ pixel. The resolution was $\sim 10 \mu \mathrm{m}$, since the observation area was approximately $6 \mathrm{~mm} \times 5 \mathrm{~mm}$, and the InSb IR camera had $640 \times 512$ pixels. Generally, the $S / N$ ratio decreased as the area of the averaging temperature decreased. Thus, it is likely that an optimal resolution existed. In this study, the data processing area was defined as $\Delta S$ with an $n \times n$ pixel $(n=1,2,4,6,8,10)$. Moreover, $\Delta S$ shows the averaging temperature of the designated area. For example, if the temperature is collected by a $1 \times 1$ pixel $(n=1)$, then $\Delta S$ is $100 \mu \mathrm{m}^{2}$. The resolution $f(\Delta S)$ 
is expressed as follows:

$$
\begin{aligned}
f(\Delta S) & =\frac{1}{\Delta S}\left(\int_{x=0}^{\infty} T(\Delta x) \mathrm{d} x+\int_{y=0}^{\infty} T(\Delta y) \mathrm{d} y\right) \\
& =\frac{1}{\Delta S} \iint_{x=0, y=0} T(\Delta x, \Delta y) \mathrm{d} x \mathrm{~d} y
\end{aligned}
$$

Equation (1) represents the relationship between the area of the average temperature and the resolution. The resolution increases as the value of $\Delta S$ decreases.
Figure 7(a) shows the normalized temperature profile depending on the area of the averaging temperature. The temperature difference between each $\Delta S$ (Fig. 7(b)) clearly decreases as the area of the averaging temperature increases. Moreover, the relatively high temperature point for all the data, which was approximately positioned in the middle of the distance between A and B, likely indicates the crack in Fig. 5. The temperature difference decreased significantly above the $4 \times 4$ pixel, which means
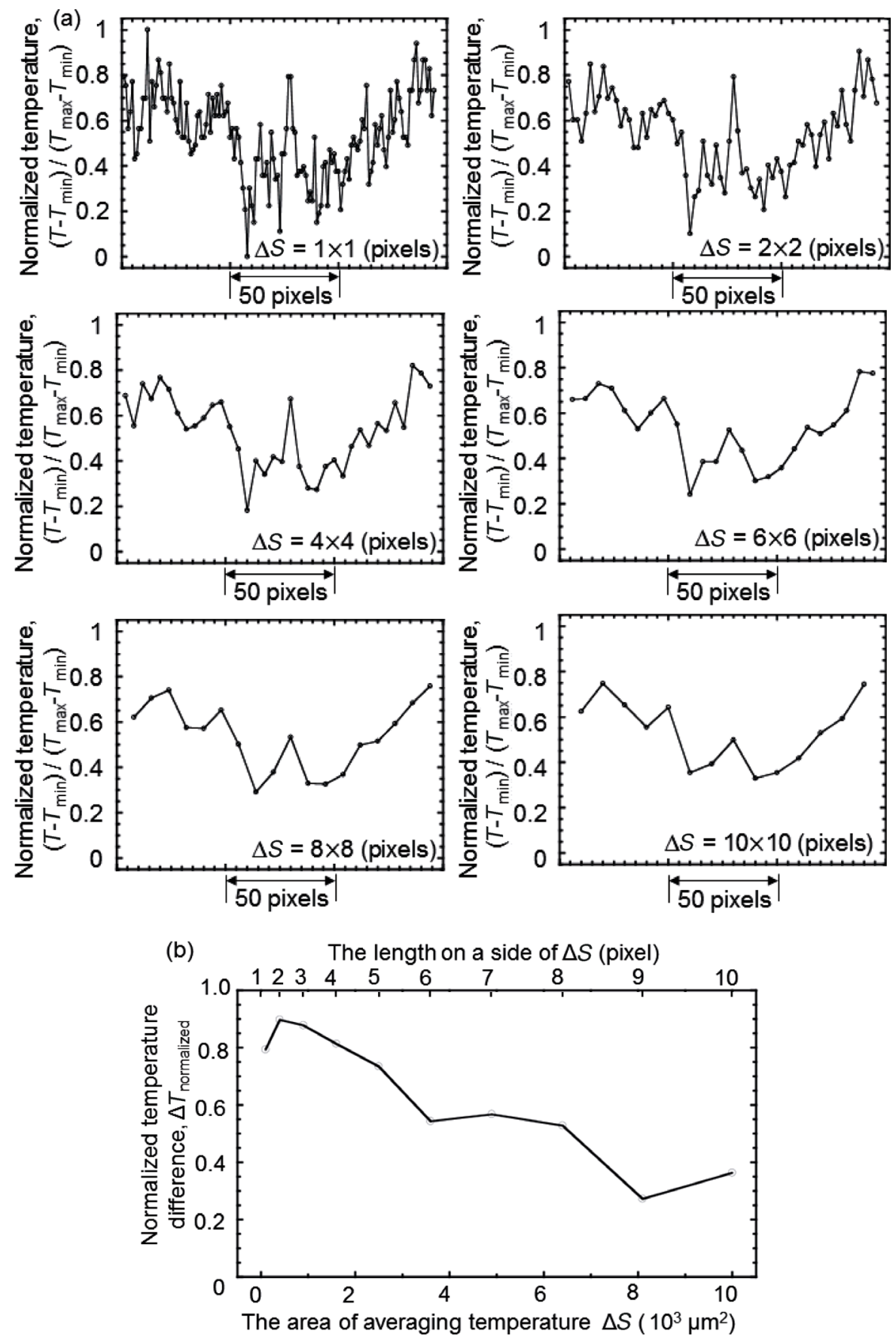

Fig. 7 Example of data processing: (a) relationship between normalized temperature and area of averaging temperature, and (b) normalized temperature difference between crack and low temperature point. 
that the temperature resolution decreased dramatically above this point. Furthermore, the normalized temperature reached almost 0 for the $2 \times 2$ and $4 \times 4$ pixels in the vicinity of the crack and the distance between the cracks $\left(25.5^{\circ} \mathrm{C}\right)$. Additionally, the lower temperature area $\left(25.3{ }^{\circ} \mathrm{C}\right)$ was approximately $10-25$ pixels. Thus, if the distance between the crack and the low temperature point is selected as an example of determining the temperature baseline, then the low temperature would be spread 100-200 $\mu \mathrm{m}$ around the crack.

Figure 8 shows the distribution of the delamination crack length, which is measured by the typical cross section of the heat-exposed EBC system. The definition of the crack length $\lambda_{\mathrm{L}}$ and $\lambda_{\mathrm{R}}$ is also shown in Fig. 8 . For both cracks, the crack length was approximately 50-150 $\mu \mathrm{m}$. Therefore, the lower temperature region shown in Figs. 5 and 6 exhibits the existence of these cracks. Therefore, the optimal area of the averaging temperature likely existed within $\Delta S=400-1600 \mu \mathrm{m}^{2}$. Moreover, it was possible to detect the delamination in the EBC system by using the PT with the optimal area of the averaging temperature. In this study, it was clearly revealed that the range of the delamination length in the EBC system could be evaluated by the PT and by choosing the area of the averaging temperature $(\Delta S)$.

During measuring of temperature profiles of EBC system by PT, heat conduction is unsteady state because temperature difference among crack, higher temperature region, and lower temperature region appears only after $\sim 100$ ms (see Fig. 5(c)). Figure 9(a) shows models for unsteady state heat conduction. Then, mullite/Si/RBSC model and mullite/air/RBSC are simulations for non-defect region and defect region in EBC system, respectively. The detailed calculation for unsteady state heat conduction in these models is described in Appendix. Figure 9(b) exhibits temperature profile for non-defect region and defect region. For non-defect

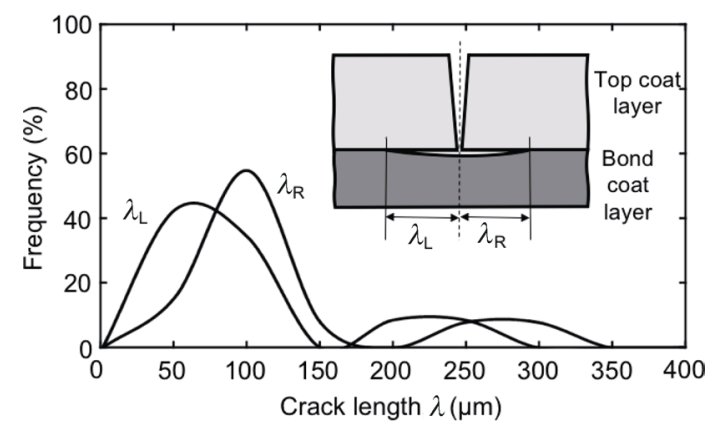

Fig. 8 Distribution of delamination crack length.
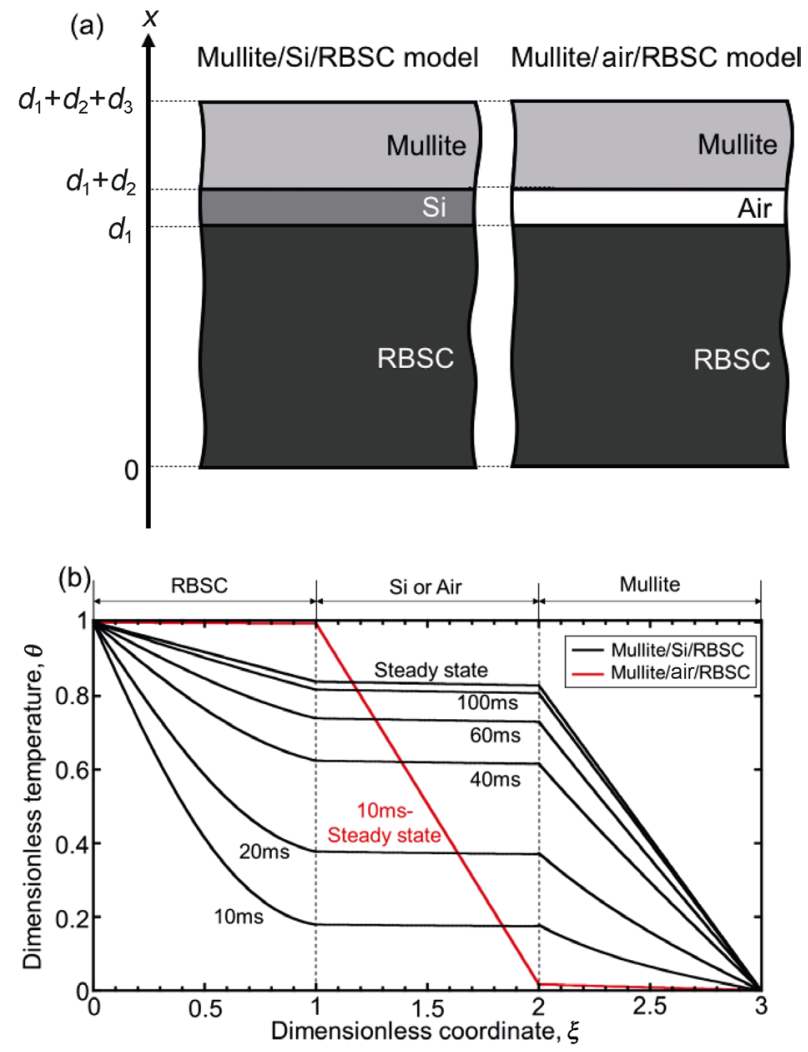

Fig. 9 (a) Analytical EBC model for temperature distribution evolved by PT, (b) dimensionless temperature profile in $\mathrm{EBC}$ system as a function of dimensionless coordinate system.

region, heat conduction from RBSC to mullite occurs after heating and the temperature profiles after $100 \mathrm{~ms}$ from heating is similar to steady state. For defect region, air acts as barrier for heat conduction. Thus, heat conduction from RBSC to mullite is inhibited. These simulations suggest that heat in EBC system is mainly conducted in non-defect region and a heat conduction decay occurs by the existence of defect region. In addition, the temperature difference between unsteady state and steady state disappears after approximately $100 \mathrm{~ms}$ and this is in good agreement with the result shown in Fig. 5. Thus, the delamination in mullite/Si/RBSC system is detectable until $\sim 100 \mathrm{~ms}$ after heating by PT to determine optimal processing area of the averaging temperature $(\Delta S)$ for the analysis of temperature profile. To apply PT as an industrial inspection method for EBC system, the determination of optimal area of the averaging temperature for $\mathrm{EBC}$ systems is required. In other words, to determine the optimal processing area, PT method is useful for other multi-layered materials composed of the different thermal properties. 


\section{Conclusions}

In this study, an evaluation method of delamination in multi-layered material composed of different thermal conductivity and thickness by PT was proposed. As an example, the delamination behavior of the top coat layer in the mullite/Si/RBSC EBC system was evaluated by PT and X-ray CT. To determine the moderate processing area of $\Delta S$, the EBC system used in this study had a mullite top coat layer delamination with a size of 100-200 $\mu \mathrm{m}$, and the delamination area of the mullite top coat layer from the RBSC substrate was detectable by the PT, because the analysis resolution for the temperature distribution, which evolved by heating, depended on $\Delta S$. The temperature distribution in the mullite top coat layer agrees with the delamination detected by the X-ray CT method and the temperature difference between the mullite top coat layers. In addition, the temperature difference between non-defect region and defect region measured by PT is in good agreement with it simulated by unsteady state heat conduction in EBC system. For detection of determination, the moderate processing area of $\Delta S$ is important. This study focused on detection of partial interface delamination in multilayered ceramics; however, PT method is applicable to other multi-layered systems for detection of delamination.

\section{Appendix}

To simulate heat conduction in EBC system used in the present study, the calculation of unsteady state heat conduction for multilayered materials proposed by Sun and Wichman [26] is applied to models shown in Fig. 9(a). $d_{1}, d_{2}$, and $d_{3}$ are the thickness, $k_{1}, k_{2}$, and $k_{3}$ are the thermal conductivity, and $\alpha_{1}, \alpha_{2}$, and $\alpha_{3}$ are thermal diffusivity of RBSC, Si, and mullite, respectively. At time $t=0$, the temperature at the top surface of mullite and the bottom surface of RBSC become $T_{0}$ and $T_{1}$. Here, dimensionless temperature $(\theta)$, coordinate system $(\xi)$, time $(\tau)$, and thermal diffusivity $(\delta)$ are defined to analyze unsteady state heat conduction as follows: $\theta=\left(T-T_{0}\right) /\left(T_{1}-T_{0}\right)$, $\xi_{1}=x / d_{1}, \quad \xi_{2}=\left(x-d_{1}\right) / d_{2}, \quad \xi_{3}=\left[x-\left(d_{1}+d_{2}\right)\right] /$ $d_{3}, \quad \tau=t / t_{0}, \quad \delta_{i}=\alpha_{i} t_{0} / d_{i}^{2}$ for $i=1,2,3 . t_{0}$ is reference time and set as $10 \mathrm{~s}$. Heat flux $\left(\kappa_{i}\right)$ is defined as $\kappa_{i}=k_{i} / d_{i}$ for $i=1,2,3$. Then, initial condition for heat conduction is written as follows [26]:

$$
\frac{\partial \theta}{\partial \tau}=\delta_{i} \frac{\partial^{2} \theta}{\partial \xi_{i}^{2}} \quad \text { (in the } i \text { th layer) }
$$

$$
\left.\theta\right|_{\xi_{1}=0}=1,\left.\theta\right|_{\xi_{1}=1}=0 \text { (boundary condition) }
$$

$\left.\theta\right|_{\xi_{1} \rightarrow 1^{-}}=\left.\theta\right|_{\xi_{2} \rightarrow 0^{+}}=0 \quad$ (continuity of temperature)

$-\left.\kappa_{1} \frac{\partial \theta}{\partial \xi_{1}}\right|_{\xi_{1} \rightarrow 1^{-}}=-\left.\kappa_{2} \frac{\partial \theta}{\partial \xi_{2}}\right|_{\xi_{2} \rightarrow 0^{+}} \quad$ (continuity of flux) (A4)

$\left.\theta\right|_{\xi_{2} \rightarrow 1^{-}}=\left.\theta\right|_{\xi_{3} \rightarrow 0^{+}}=0$ (continuity of temperature)

$-\left.\kappa_{2} \frac{\partial \theta}{\partial \xi_{2}}\right|_{\xi_{2} \rightarrow 1^{-}}=-\left.\kappa_{3} \frac{\partial \theta}{\partial \xi_{3}}\right|_{\xi_{3} \rightarrow 0^{+}}$(continuity of flux)(A6)

$$
\left.\theta\right|_{\tau=0}=0 \quad \text { (initial condition) }
$$

Then, $\theta$ is depending on $\xi_{i}$ and $\tau$, and described as following equations [26]:

$$
\begin{gathered}
\theta\left(\xi_{i}, \tau\right)=\left[1-(\Delta \theta)_{1} \xi_{1}\right] \\
-\sum_{n=0}^{\infty} A_{n} \exp \left(-\lambda_{n}^{2} \delta_{1} \tau\right) X_{n}^{1}\left(\xi_{1}\right) \text { (layer 1) } \\
\theta\left(\xi_{i}, \tau\right)=\left[1-(\Delta \theta)_{1}-(\Delta \theta)_{2} \xi_{2}\right] \\
-\Delta_{1} \sum_{n=0}^{\infty} A_{n} \exp \left(-\lambda_{n}^{2} \delta_{2} \tau\right) X_{n}^{2}\left(\xi_{2}\right) \quad \text { (layer 2)(A8) } \\
\theta\left(\xi_{i}, \tau\right)=\left[1-(\Delta \theta)_{1}-(\Delta \theta)_{2}-(\Delta \theta)_{3} \xi_{3}\right] \\
-\Delta_{2} \sum_{n=0}^{\infty} A_{n} \exp \left(-\lambda_{n}^{2} \delta_{3} \tau\right) X_{n}^{2}\left(\xi_{3}\right) \quad \text { (layer 3) }
\end{gathered}
$$

Then, $\lambda_{n}$ is eigenvalue and satisfy:

$$
\tan \left(\lambda_{n}\right)=\frac{\left[\Delta_{1} \tan \left(\sqrt{\frac{\delta_{1}}{\delta_{2}}} \lambda_{n}\right)+\Delta_{2} \tan \left(\sqrt{\frac{\delta_{1}}{\delta_{3}}} \lambda_{n}\right)\right]}{\left[1-\left(\Delta_{2} / \Delta_{1}\right) \tan \left(\sqrt{\frac{\delta_{1}}{\delta_{2}}} \lambda_{n}\right) \tan \left(\sqrt{\frac{\delta_{1}}{\delta_{3}}} \lambda_{n}\right)\right]} \text { (A9) }
$$

and $X_{n}^{i}\left(\xi_{i}\right)$ is eigenfunction and described as

$$
\begin{aligned}
& X_{n}^{1}\left(\xi_{1}\right)=\sin \left(\lambda_{n} \xi_{1}\right) X_{n}^{2}\left(\xi_{2}\right)= \\
& \cos \left(\lambda_{n}\right) \sin \left(\sqrt{\frac{\delta_{1}}{\delta_{2}}} \lambda_{n} \xi_{2}\right) \\
&+\frac{\sin \left(\lambda_{n}\right)}{\Delta_{1}} \cos \left(\sqrt{\frac{\delta_{1}}{\delta_{2}}} \lambda_{n} \xi_{2}\right) \\
& X_{n}^{3}\left(\xi_{3}\right)=\bar{\alpha}_{n} \sin \left(\sqrt{\frac{\delta_{1}}{\delta_{3}}} \lambda_{n} \xi_{3}\right)+\bar{\beta}_{n} \cos \left(\sqrt{\frac{\delta_{1}}{\delta_{3}}} \lambda_{n} \xi_{3}\right)
\end{aligned}
$$


where $\bar{\alpha}_{n}$ and $\bar{\beta}_{n}$ are shown as follows:

$\bar{\alpha}_{n}=\cos \left(\lambda_{n}\right) \cos \left(\sqrt{\frac{\delta_{1}}{\delta_{2}}} \lambda_{n}\right)-\frac{\sin \left(\lambda_{n}\right) \sin \left(\sqrt{\frac{\delta_{1}}{\delta_{2}}} \lambda_{n}\right)}{\Delta_{1}}(\mathrm{~A} 13)$ $\bar{\beta}_{n}=\frac{\Delta_{1} \cos \left(\lambda_{n}\right) \sin \left(\sqrt{\frac{\delta_{1}}{\delta_{2}}} \lambda_{n}\right)}{\Delta_{2}}+\frac{\sin \left(\lambda_{n}\right) \cos \left(\sqrt{\frac{\delta_{1}}{\delta_{2}}} \lambda_{n}\right)}{\Delta_{2}}$

Parameter $A_{n}$ is also depending on $\lambda_{n}$ and described below:

$$
\begin{gathered}
A_{n}=\frac{\kappa_{2} \kappa_{3}}{\lambda_{n} M_{n}} \\
M_{n}=\frac{\kappa_{2} \kappa_{3}}{2}+\frac{\kappa_{1} \kappa_{3}}{2}\left[\frac{\cos ^{2}\left(\lambda_{n}\right)+\sin ^{2}\left(\lambda_{n}\right)}{H_{1}^{2}}\right]
\end{gathered}
$$

Table A2 Calculation parameters for mullite/Si/RBSC

\begin{tabular}{|c|c|c|c|c|c|}
\hline$n$ & $\lambda_{n}$ & $\bar{\alpha}_{n}$ & $\beta_{n}$ & $M_{n}$ & $A_{n}$ \\
\hline 1 & 1.570 & -0.03701 & 0.1667 & $3.030 \mathrm{E}+10$ & 1.083 \\
\hline 2 & 3.524 & -0.8875 & -0.09575 & $1.333 \mathrm{E}+11$ & 0.1097 \\
\hline 3 & 4.722 & 0.1226 & -0.1637 & $3.199 \mathrm{E}+10$ & 0.3410 \\
\hline 4 & 7.000 & 0.6168 & 0.1601 & $8.099 \mathrm{E}+10$ & 0.09084 \\
\hline 5 & 7.925 & -0.2551 & 0.1530 & $3.820 \mathrm{E}+10$ & 0.1701 \\
\hline 6 & 10.37 & -0.3417 & -0.1862 & $4.690 \mathrm{E}+10$ & 0.1059 \\
\hline 7 & 11.24 & 0.4739 & -0.1194 & $5.824 \mathrm{E}+10$ & 0.07867 \\
\hline 8 & 13.61 & 0.1641 & 0.1929 & $3.520 \mathrm{E}+10$ & 0.1075 \\
\hline 9 & 14.67 & -0.7162 & 0.0475 & $9.519 \mathrm{E}+10$ & 0.03688 \\
\hline 10 & 16.77 & -0.0591 & -0.1954 & $3.220 \mathrm{E}+10$ & 0.09538 \\
\hline 11 & 18.17 & 0.8453 & 0.0557 & $1.225 \mathrm{E}+11$ & 0.02314 \\
\hline 12 & 19.91 & -0.0284 & 0.1961 & $3.188 \mathrm{E}+10$ & 0.08114 \\
\hline 13 & 21.67 & -0.7788 & -0.1550 & $1.112 \mathrm{E}+11$ & 0.02137 \\
\hline 14 & 23.06 & 0.1236 & -0.1926 & $3.361 \mathrm{E}+10$ & 0.06644 \\
\hline 15 & 25.11 & 0.5733 & 0.2204 & $7.758 \mathrm{E}+10$ & 0.02644 \\
\hline 16 & 26.26 & -0.2526 & 0.1774 & $3.928 \mathrm{E}+10$ & 0.04993 \\
\hline 17 & 28.46 & -0.3397 & -0.2500 & $5.103 \mathrm{E}+10$ & 0.03546 \\
\hline 18 & 29.55 & 0.4217 & -0.1371 & $5.266 \mathrm{E}+10$ & 0.03310 \\
\hline 19 & 31.68 & 0.1707 & 0.2593 & $4.016 \mathrm{E}+10$ & 0.04048 \\
\hline 20 & 32.95 & -0.5837 & 0.0576 & $7.217 \mathrm{E}+10$ & 0.02166 \\
\hline
\end{tabular}
model (non-defect region)

\section{References}

[1] Lee KN, Fox DS, Eldridge JI, et al. Upper temperature limit of environmental barrier coatings based on mullite

$$
+\frac{\kappa_{1} \kappa_{2}}{2}\left(\bar{\alpha}_{n}^{2}+\beta_{n}^{2}\right)
$$

For calculation of $\lambda_{n}, A_{n}$, and $M_{n}$, the value of $n$ is set as 20 in accordance with similar calculation conducted by Sun and Wichman [26]. The values in Table A1 is used for these calculations and parameters such as $\lambda_{n}, \bar{\alpha}_{n}, \bar{\beta}_{n}, A_{n}$, and $M_{n}$ are also summarized in Tables A2 and A3.

Table A1 Basic properties of components in mullite/ Si/RBSC EBC system $[10,11,22,27-29]$

\begin{tabular}{ccccc}
\hline & $\begin{array}{c}\text { Thickness } \\
(\mu \mathrm{m})\end{array}$ & $\begin{array}{c}\text { Density } \\
\left(\mathrm{g} / \mathrm{cm}^{3}\right)\end{array}$ & $\begin{array}{c}\text { Thermal } \\
\text { conductivity } \\
(\mathrm{W} /(\mathrm{m} \cdot \mathrm{K}))\end{array}$ & $\begin{array}{c}\text { Heat capacity } \\
(\mathrm{J} /(\mathrm{kg} \cdot \mathrm{K}))\end{array}$ \\
\hline Mullite & 240 & 3.2 & 6 & 781 \\
$\mathrm{Si}$ & 60 & 2.33 & 124 & 712 \\
$\mathrm{RBSC}$ & 2000 & 3 & 220 & 687 \\
\hline
\end{tabular}

Table A3 Calculation parameters for mullite/air/RBSC model (defect region)

\begin{tabular}{cccccc}
\hline$n$ & $\lambda_{n}$ & $\bar{\alpha}_{n}$ & $\beta_{n}$ & $M_{n}$ & $A_{n}$ \\
\hline 1 & 61.3 & -0.03893 & 0.02773 & $1.260 \mathrm{E}+07$ & $1.308 \mathrm{E}-02$ \\
2 & 122.5 & -0.9998 & -0.7670 & $1.660 \mathrm{E}+09$ & $4.965 \mathrm{E}-05$ \\
3 & 183.7 & -0.08307 & -0.05646 & $2.147 \mathrm{E}+07$ & $2.561 \mathrm{E}-03$ \\
4 & 245.0 & 0.9990 & 1.533 & $1.704 \mathrm{E}+09$ & $2.420 \mathrm{E}-05$ \\
5 & 306.3 & 0.005283 & 0.1350 & $1.062 \mathrm{E}+07$ & $3.106 \mathrm{E}-03$ \\
6 & 367.5 & -0.9978 & -2.297 & $1.775 \mathrm{E}+09$ & $1.548 \mathrm{E}-05$ \\
7 & 428.6 & -0.2254 & 0.5348 & $1.007 \mathrm{E}+08$ & $2.341 \mathrm{E}-04$ \\
8 & 489.9 & 0.9823 & -0.6403 & $1.599 \mathrm{E}+09$ & $1.289 \mathrm{E}-05$ \\
9 & 551.4 & -0.05047 & -0.3407 & $1.727 \mathrm{E}+07$ & $1.060 \mathrm{E}-03$ \\
10 & 612.5 & -0.9939 & -3.813 & $2.003 \mathrm{E}+09$ & $8.234 \mathrm{E}-06$ \\
11 & 673.6 & -0.2683 & 0.2460 & $1.294 \mathrm{E}+08$ & $1.159 \mathrm{E}-04$ \\
12 & 734.8 & 0.9452 & -2.683 & $1.658 \mathrm{E}+09$ & $8.290 \mathrm{E}-06$ \\
13 & 796.1 & 0.2895 & -0.05205 & $1.473 \mathrm{E}+08$ & $8.613 \mathrm{E}-05$ \\
14 & 857.4 & -0.9677 & -1.596 & $1.608 \mathrm{E}+09$ & $7.325 \mathrm{E}-06$ \\
15 & 918.6 & -0.3106 & -0.1745 & $1.687 \mathrm{E}+08$ & $6.516 \mathrm{E}-05$ \\
16 & 979.9 & 0.9619 & 2.324 & $1.664 \mathrm{E}+09$ & $6.195 \mathrm{E}-06$ \\
17 & 1041 & 0.4241 & -1.053 & $3.331 \mathrm{E}+08$ & $2.913 \mathrm{E}-05$ \\
18 & 1102 & -0.7654 & 8.966 & $3.051 \mathrm{E}+09$ & $3.004 \mathrm{E}-06$ \\
19 & 1164 & 0.03990 & 0.5470 & $2.046 \mathrm{E}+07$ & $4.242 \mathrm{E}-04$ \\
20 & 1225 & 0.9756 & 7.485 & $3.018 \mathrm{E}+09$ & $2.732 \mathrm{E}-06$ \\
\hline & & & & &
\end{tabular}

and BSAS. J Am Ceram Soc 2003, 86: 1299-1306.

[2] Lee KN, Fox DS, Bansal NP. Rare earth silicate environmental barrier coatings for $\mathrm{SiC} / \mathrm{SiC}$ composites and $\mathrm{Si}_{3} \mathrm{~N}_{4}$ ceramics. J Eur Ceram Soc 2005, 25: 1705-1715.

[3] Cojocaru CV, Kruger SE, Moreau C, et al. Elastic modulus evolution and behavior of $\mathrm{Si} /$ mullite/BSAS-based 
environmental barrier coatings exposed to high temperature in water vapor environment. $J$ Therm Spray Tech 2011, 20: 92-99.

[4] Cojocaru CV, Lévesque D, Moreau C, et al. Performance of thermally sprayed $\mathrm{Si} /$ mullite/BSAS environmental barrier coatings exposed to thermal cycling in water vapor environment. Surf Coat Technol 2013, 216: 215-223.

[5] Richards BT, Wadley HNG. Plasma spray deposition of tri-layer environmental barrier coatings. J Eur Ceram Soc 2014, 34: 3069-3083.

[6] Richards BT, Begley MR, Wadley HNG. Mechanisms of ytterbium monosilicate/mullite/silicon coating failure during thermal cycling in water vapor. $J$ Am Ceram Soc 2015, 98: 4066-4075.

[7] Richards BT, Sehr S, de Franqueville F, et al. Fracture mechanisms of ytterbium monosilicate environmental barrier coatings during cyclic thermal exposure. Acta Mater 2016, 103: 448-460.

[8] Richards BT, Young KA, de Francqueville F, et al. Response of ytterbium disilicate-silicon environmental barrier coatings to thermal cycling in water vapor. Acta Mater 2016, 106: 1-14.

[9] Schneider H. Thermal properties of mullite. In: Mulitte. Schneider H, Komarneni S, Eds. Willey-VCH, 2005: 149-164.

[10] Okada Y, Tokumaru Y. Precise determination of lattice parameter and thermal expansion coefficient of silicon between 300 and 1500 K. J Appl Phys 1984, 56: 314-320.

[11] Langen M, Hibiya T, Eguchi M, et al. Measurement of the density and the thermal expansion coefficient of molten silicon using electromagnetic levitation. J Cryst Growth 1998, 186: 550-556.

[12] Lee KN, Miller RA, Jacobson NS. New generation of plasma-sprayed mullite coatings on silicon carbide. $J \mathrm{Am}$ Ceram Soc 1995, 78: 705-710.

[13] Inoue R, Arai Y, Kakisawa H. In situ observation and strain distribution measurements of atmospheric plasma-sprayed mullite and $\mathrm{Si}$ multilayered coatings on $\mathrm{SiC}$ substrates. $J$ Mater Sci 2019, 54: 2824-2835.

[14] Arai Y, Aoki Y, Kagawa Y. Effect of cristobalite formation on the delamination resistance of an oxide $/ \mathrm{Si} /(\mathrm{SiC} / \mathrm{SiC})$ environmental barrier coating system after cyclic high temperature thermal exposure. Scripta Mater 2017, 139: $58-62$.

[15] Arai Y, Kagawa Y. Change of microstructure in environmental barrier coating on Si-contained ceramic substrate after melting and solidification of Si bond coat layer. J Gas Turbine Soc Jpn 2018, 46: 57-61. (in Japanese)

[16] Arai Y, Sato M, Kagawa Y. Melting/solidification of Si bond coat layer in oxide/Si/RB-SiC environmental barrier coating system. Adv Eng Mater 2018, 20: 1800677.

[17] Spitsberg I, Steibel J. Thermal and environmental barrier coatings for $\mathrm{SiC} / \mathrm{SiC} \mathrm{CMCs}$ in aircraft engine applications. Int J Appl Ceram Technol 2005, 1: 291-301.

[18] Bhatt RT, Choi SR, Cosgriff LM, et al. Impact resistance of environmental barrier coated $\mathrm{SiC} / \mathrm{SiC}$ composites. Mater Sci Eng 2008, 476: 8-19.

[19] Ramachandra C, Lee KN, Tewari SN, et al. Spectroscopic nondestructive evaluation of environmental barrier coating failure on silicon-based ceramics. J Am Ceram Soc 2004, 87: $1117-1121$.

[20] Bhatt RT, Choi SR, Cosgriff LM, et al. Impact resistance of uncoated $\mathrm{SiC} / \mathrm{SiC}$ composites. Mat Sci Eng A 2008, 476: $20-28$.

[21] Kimmel J, Miriyala N, Price J, et al. Evaluation of CFCC liners with EBC after field testing in a gas turbine. $J$ Eur Ceram Soc 2002, 22: 2769-2775.

[22] Munro RG. Material properties of a sintered $\alpha$-SiC. J Phys Chem Ref Data 1997, 26: 1195-1203.

[23] Montgomery RB. Viscosity and thermal conductivity of air and diffusivity of water vapor in air. J Meteor 1947, 4: 193-196.

[24] Maillet D, Houlbert A, Didierjean S, et al. Non-destructive thermal evaluation of delaminations in a laminate: Part I-Identification by measurement of thermal contrast. Compos Sci Technol 1993, 47: 137-153.

[25] Maillet D, Houlbert A, Didierjean S, et al. Non-destructive thermal evaluation of delaminations in a laminate: Part II-The experimental Laplace transforms method. Compos Sci Technol 1993, 47: 155-172.

[26] Sun YZ, Wichman IS. On transient heat conduction in a one-dimensional composite slab. Int $J$ Heat Mass Trans 2004, 47: 1555-1559.

[27] Hildmann B, Schneider H. Heat capacity of mullite- New data and evidence for a high-temperature phase transformation. $J$ Am Ceram Soc 2004, 87: 227-234.

[28] Desai PD. Thermodynamic properties of iron and silicon. $J$ Phys Chem Ref Data 1986, 15: 967-983.

[29] Cardarelli F. Materials Handbook. Springer London, 2000.

Open Access This article is licensed under a Creative Commons Attribution 4.0 International License, which permits use, sharing, adaptation, distribution and reproduction in any medium or format, as long as you give appropriate credit to the original author(s) and the source, provide a link to the Creative Commons licence, and indicate if changes were made.

The images or other third party material in this article are included in the article's Creative Commons licence, unless indicated otherwise in a credit line to the material. If material is not included in the article's Creative Commons licence and your intended use is not permitted by statutory regulation or exceeds the permitted use, you will need to obtain permission directly from the copyright holder.

To view a copy of this licence, visit http://creativecommons.org/licenses/by/4.0/. 